American Journal of Pharmaceutical Education 2016; 80 (8) Article 132.

\title{
RESEARCH
}

\section{Pharmacy Educator Motives to Pursue Pedagogical Knowledge}

\author{
Patricia Baia, PhD, Aimee F. Strang, PharmD \\ Albany College of Pharmacy and Health Sciences, Albany, New York \\ Submitted July 31, 2015; accepted December 9, 2015; published October 25, 2016.
}

Objective. To investigate motives of pharmacy educators who pursue pedagogical knowledge through professional development programs and to develop a model of motivation to inform future development.

Methods. A mixed-methods approach was used to study both qualitative and quantitative data. Written narratives, postmodule quizzes, and survey data were collected during a 5-year period (2010-2014) from pharmacy educators who participated in an online professional development program titled Helping Educators Learn Pedagogy (HELP). Grounded theory was used to create a model of motivation for why pharmacy educators might pursue pedagogical knowledge.

Results. Participants reported being driven intrinsically by a passion for their own learning (selfcentered motivation) and by the need to improve student learning (student-centered motivation) and extrinsically by program design, funding, and administrator encouragement.

Conclusion. A new model of pharmacy educator motivation to pursue pedagogy knowledge, Pedagogical Knowledge Acquisition Theory (PKAT), emerged as a blended intrinsic and extrinsic model, which may have value in developing future professional development programs.

Keywords: pharmacy faculty, motives, pedagogy, professional development, grounded theory

\section{INTRODUCTION}

The pursuit of knowledge for health educators is crucial and, in fact, mandatory through continuing education to obtain clinical content knowledge in licensed health professions. ${ }^{1-3}$ However, the pursuit of pedagogical knowledge for health educators through professional development is not mandatory. Pedagogical knowledge is defined as the understanding and skills needed in teaching theory and practice. ${ }^{4-6}$ In addition, pedagogical knowledge is recognized as valuable for teachers through the Technological Pedagogical Content Knowledge (TPACK) framework (Figure 1). ${ }^{4}$ The TPACK framework emphasizes the integration and intersection of three key knowledge areas for effective teaching: (1) Technology Knowledge - knowledge of technology as a resource and tool for teaching; (2) Pedagogical Knowledge - knowledge of teaching theory and practice as it relates to students and content; and (3) Content Knowledge - knowledge of a specialized content or topic area.

While content knowledge is typically emphasized as a critical component for health educators, the other two areas are not as well recognized. The lack of mandatory

Corresponding Author: Patricia Baia, Albany College of Pharmacy and Health Sciences, 106 New Scotland Ave., Albany, NY 12208. Tel: 518-694-7233. Fax: 518-694-7382. E-mail: patricia.baia@acphs.edu professional development in these areas for health educators is well described, ${ }^{5-7}$ and is gaining attention as a problem in higher education. ${ }^{2,8-14}$ The Accreditation Council for Pharmacy Education (ACPE) put increased emphasis on the art and practice of teaching and the assessment of student learning in its 2016 Accreditation Standards and Guidelines. ${ }^{15}$ The American Association of Colleges of Pharmacy (AACP) and the American College of Clinical Pharmacy (ACCP) dedicated programs to support faculty needs in teaching and learning. ${ }^{16,17}$ Because professional development in pedagogical knowledge remains voluntary, the question moves toward what motivates pharmacists in higher education to pursue pedagogical knowledge.

A fair amount is already known about internal and external motivations for participation in clinical content knowledge in the pharmacy profession. Intrinsic motivation is defined as being driven by an internal source (ie, to learn something new), and extrinsic motivation is defined as being driven by an external source (ie, receiving money). In addition to being a mandatory part of licensure, other external motivations include time, funding, and administrative support. ${ }^{18-25}$ Internal motivations to attend clinical continuing education programs include personal desire to learn and desire to demonstrate expertise. $^{1,3}$ There is a paucity of literature on what motivates pharmacy faculty members to participate in voluntary 


\section{American Journal of Pharmaceutical Education 2016; 80 (8) Article 132.}

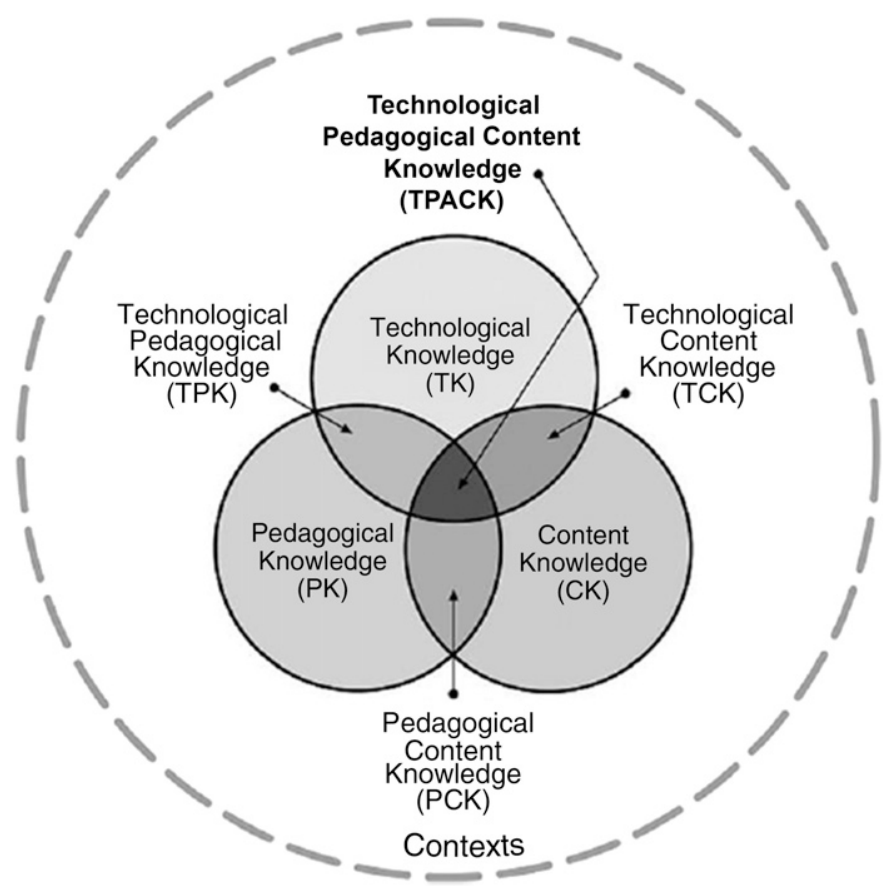

Figure 1. Diagram of Technological Pedagogical Content Knowledge (TPACK) Framework. Reproduced and adopted by permission of the publisher (http://tpack.org).

pedagogical knowledge development. Motivation is defined in this study as the inspiration behind human behavior. ${ }^{18}$ The study explored pharmacy educator motives to pursue life-long learning in pedagogical knowledge through professional development to build a behavioral model that describes motivation.

\section{METHODS}

Pharmacy educators are defined in this study as faculty or staff members employed by higher educational institutions who have teaching responsibilities (eg, instructors, preceptors, librarians, clinicians). This research focused particularly on pharmacy educators and what motivates them to pursue additional knowledge in pedagogy. A mixed-methods approach was used to collect and analyze quantitative and qualitative data from pharmacy educators involved in a pedagogy professional development program. Grounded theory was used to analyze qualitative data and create a model of motivation for why faculty members might pursue pedagogical knowledge. Grounded theory is a qualitative research design in which the inquirer generates an explanation of an action shaped by the views of participants who have experienced the action. ${ }^{26-29} \mathrm{Re}$ curring concepts and ideas in the data were used to create a motivational model. This model was then used as a lens to further explore intrinsic and extrinsic motives.

Participants were all students in a professional development program called Helping Educators Learn
Pedagogy (HELP). It is a voluntary, 50-hour online program, developed and run by two faculty members at Albany College of Pharmacy and Health Sciences (ACPHS). The program provides educators with strategies and tactics to become more effective teachers and contains six learning modules. Participants watch videos, read articles and selections of texts, and research websites as they develop new knowledge in teaching theory, assessment, lesson planning, teaching methodology, and teaching technologies. Participants apply what they learn by developing lessons and assignments that increase student engagement and enhance student understanding. An ACPHS website is used for registration and payment, and participants access the program through Blackboard (Blackboard Inc., Washington, DC). Originating in 2010, the program ran anywhere from eight to 12 weeks during the summer. Program objectives included: (1) applying pedagogical strategies and principles that make learning meaningful; (2) creating practical and manageable lessons to use instantly in your teaching; (3) adopting a variety of assessment strategies; (4) integrating appropriate technology into teaching; and (5) engaging in reflective dialogue with colleagues regarding pedagogy. Program participants consisted of faculty and staff members employed by colleges and schools of pharmacy who had teaching roles and completed the HELP program in its entirety.

Institutional review board approval was obtained through the Albany College of Pharmacy and Health Sciences; the study was classified as exempt. Data were collected through written narratives, postmodule quizzes, and a survey during a 5-year period (2010-2014). All data were deidentified. Written narratives were collected at the start of each HELP offering. Participants were asked to describe themselves and define their motivation to participate in HELP. In addition, they had to complete the following five statements: (1) I bring to teaching a belief that. ..; (2) In the classroom I see myself as. . ; (3) I believe students are...; (4) I seek to foster in students...; and (5) I think learning is. ... Narrative data were exported into Microsoft Excel, categorized by question, and analyzed for general themes of motivation.

Postmodule quiz questions were the same for each module: (1) What did you learn? (2) What helped your learning? and (3) What hindered your learning? These questions were asked to make participants reflect on their learning. Responses were free text and described in participant's own words. These data were collected for each of the six learning modules for all five years of HELP. Participant responses were exported into Excel, categorized by question, and analyzed for general themes of motivation.

A voluntary, anonymous, electronic survey was developed in 2012 to gather additional data from past 
American Journal of Pharmaceutical Education 2016; 80 (8) Article 132.

participants. Two of the questions asked about motivating factors to attend the HELP program. Participants were asked to rate the importance and availability of motivational factors using a Likert scale. Motivating factors used in the survey were informed by emergent themes in the data from the written narratives and postmodule quizzes from 2010 and 2011, and also from literature identifying typical intrinsic and extrinsic motives for life-long learning. $2,10,13,24,25,27,30$ The survey was administered in SurveyMonkey (SurveyMonkey, Palo Alto, CA) to all past participants $(2010,2011)$. Past participants were contacted via e-mail using the e-mail address they provided during the HELP program and asked to complete the survey. The survey was also added to the final program evaluations for all participants and administered three additional times at the conclusion of HELP in 2012, 2013, and 2014. Data from all five years were downloaded and collated in Excel for analysis.

Data from the written narratives and postmodule quizzes was categorized by question and were reviewed by researchers to assure accurate data entry. To analyze for general themes of motivation, the data were converted into units and coded, with each unit representing one theme or concept. Once the data were coded, they were reorganized under larger themes or subthemes. This approach allowed the authors to develop an explanation or theory — in this case a theory of motivation — based on the views of the participants. During the process of data evaluation, general themes of motivation were identified such as intrinsic or extrinsic motivations. Once these themes were identified, they were used to reassess the written narratives and postmodule quiz data, with specific examples from the text used to represent and support the themes. In addition, a word cloud was created as a visual way to gain basic understanding of participant's qualitative responses. A word cloud image displays words in different sizes depending on frequency of use and can be a good way to discover qualitative themes and patterns. ${ }^{31,32}$ Wordle (Wordle.net) was used to generate the word cloud. Themes from the word cloud were used as a lens to reanalyze the written narratives for confirmation of existing themes, or to discover additional themes. Data from the survey were analyzed in Excel for frequencies and means of participant responses.

\section{RESULTS}

One hundred ninety-two participants completed the HELP program over five years (2010-2014). Participants were Albany College of Pharmacy and Health Sciences (ACPHS) faculty members $(n=49)$ and external participants $(n=143)$ from 34 regional or national schools of pharmacy (Table 1). Participant titles ranged from adjunct,

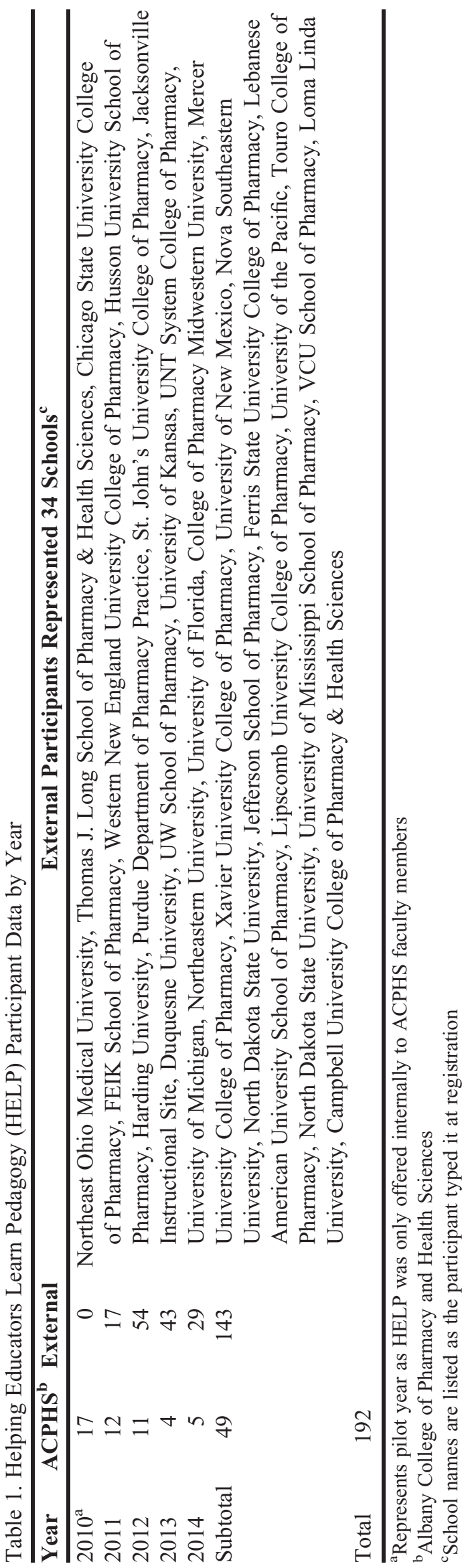




\section{American Journal of Pharmaceutical Education 2016; 80 (8) Article 132.}

instructor, assistant, and associate professor to administrator, preceptor, and clinician and were from departments typical of a school of pharmacy.

Written narratives $(n=192)$ revealed that the primary motivation to take the HELP program was fueled by intrinsic factors. There was an absence of any extrinsic motives in these written texts. Intrinsic motivators could be separated into two categories; (1) motivation to improve oneself as a teacher, which we called self-centered motivation, and (2) motivation to help students learn, which we called student-centered motivation. An example of self-centered motivation was, "... .I took this course wanting to be better, to do better, and to feel like I had achieved something, maybe a new level of knowledge in my teaching. And, I did." An example of student-centered motivation was, "...I am here to engage, facilitate, and motivate those around me. If I motivate a student on a subject matter, they will seek further information on their own. I need to focus on their spark."

Postmodule quizzes $(n=192)$ displayed similar motivational themes. Self-centered motivation and studentcentered motivation revealed themselves again as two major themes. Additional external motivators were revealed, such as program content and format. These external motives were named program design. Additional examples included responses about the coursework, availability of the program, and the online format.

Postmodule quiz data were also used to generate a word cloud to help unfold the emerging themes. The most frequently used words were "student[s], learning, and teaching." Other words that were emphasized in the word cloud were "assessment, feedback, methods, and skills," which supported the theme of self-centered motivation, and "knowledge, help, need, and student," which supported student-centered motivation. The three main words, student, learning and teaching, were then used as a lens to further analyze qualitative data from the narratives. Words, sentences, or ideas around these themes were sorted, and common or repetitive responses were exposed around each grouping. Data that included the word "learning" supported the theme of self-centered motivation, as language revolved around improving oneself as a teacher. "Student[s]" was cross-referenced to student-centered motivation, as language revolved around helping students learn. Data that contained the word "teaching" linked to self-centered motivation and seemed to provide more insight into teacher roles and responsibilities.

The optional survey was available to all 192 participants. Eighty-four participants responded (44\% response rate) during the 5-year period. Participants were asked how they became aware of the HELP program. The most common response was on the recommendation of their chair or dean (60\%), followed by a colleague (24\%), personal e-mail from the codirectors (14\%), and the AACP newsletter (11\%).

When asked about the importance of different motivations for taking the HELP program, learning about practical application topics (90\%) and theoretical topics $(60 \%)$ ranked as frequently or extensively important, supporting the extrinsic motivation of program design (Table 2). Items that did not seem to rank highly as

Table 2. Question 1 and 2 Survey Results from Helping Educators Learn Pedagogy Participants

\begin{tabular}{lcrrrrr}
\hline & $\mathbf{1}$ & $\mathbf{2}$ & $\mathbf{3}$ & $\mathbf{4}$ & $\mathbf{5}$ & Mean Score \\
\hline Q1. Rate the degree to which the following & were important & when & considering attending HELP: & & \\
Monetary incentives/rewards & 82.1 & 13.4 & 3.0 & 1.5 & 0.0 & 1.2 \\
Administrative recognition & 37.3 & 28.4 & 20.9 & 13.4 & 0.0 & 2.1 \\
Peer recognition & 37.3 & 28.4 & 26.9 & 7.5 & 0.0 & 2.0 \\
Tenure/promotion recognition & 39.4 & 7.6 & 30.3 & 19.7 & 3.0 & 2.4 \\
Release time & 60.6 & 21.2 & 7.6 & 10.6 & 0.0 & 1.7 \\
May lead to publication & 68.2 & 15.2 & 12.1 & 4.5 & 0.0 & 1.5 \\
Practical application content & 0.0 & 3.0 & 6.0 & 37.3 & 53.7 & 4.4 \\
Theoretical content & 6.0 & 4.5 & 29.9 & 38.8 & 20.9 & 3.6 \\
Q2. Rate the degree to which the following & were available & when considering attending HELP: & & \\
Internal/onsite opportunities & 29.9 & 14.9 & 22.4 & 22.4 & 10.4 & 2.7 \\
Funding & 24.2 & 4.5 & 12.1 & 19.7 & 39.4 & 3.5 \\
Faculty retreats & 49.3 & 16.4 & 20.9 & 10.4 & 3.0 & 2.0 \\
Tenure/promotion recognition & 43.1 & 18.5 & 21.5 & 12.3 & 4.6 & 2.2 \\
Release time & 68.7 & 13.4 & 10.4 & 6.0 & 1.5 & 1.6 \\
One-on-one assistance & 44.8 & 17.9 & 22.4 & 11.9 & 3.0 & 2.1 \\
Faculty "show and tell" & 48.5 & 24.2 & 15.2 & 10.6 & 1.5 & 1.9 \\
\hline
\end{tabular}

Percentages are used in this table to represent survey data

$1=$ never, $5=$ extensively 


\section{American Journal of Pharmaceutical Education 2016; 80 (8) Article 132.}

motivators included administrative recognition, peer recognition, release time, and the ability to lead to scholarship or publication. Monetary incentives/rewards had the lowest importance, with $96 \%$ of participants saying it was rarely or never important in their decision. When asked about availability of resources as potential motivators, funding was the highest, with $59 \%$ of participants indicating it was frequently or extensively available. Release time from work was the least available resource, with $82 \%$ of participants saying it was rarely or never available.

Using grounded theory to understand data from the narratives, postmodule quizzes, and the survey, three distinct areas emerged from participants to describe their motivation: self-centered motivation, student-centered motivation, or program design. Using this lens to understand the data, these areas can be better described.

Self-centered motivation was defined as wanting to improve oneself as a teacher, an intrinsic motive. In postmodule quiz data, there were two ways in which participants wanted to do this: become a better teacher through HELP and recognize the need to pursue life-long learning in pedagogy. Some participants wanted to become better teachers because they recognized their deficiencies. One participant said, "I have already mastered my clinical area, but teaching is something I have to work on." Others wanted to learn new tools, skills, or methods in the classroom: "Lesson planning is critical and using technology in the classroom is scary, I need help." Still others commented on gaining a better understanding of teaching and learning. Examples of this included, "I did the HELP program to be a better teacher. I learned I was doing a pretty good job, but now I know why."

The pursuit of life-long learning in pedagogy as a significant motivator was evident in responses. Participants recognized the continual need for self-improvement and development to be successful teachers. Examples of this included, "Teachers should always be learning and bringing in new ideas," "You should never get too comfortable, learning more on what you can do for your students is crucial," and "I have an enthusiasm for knowledge and life-long learning, I think learning is. . fun!"

Interestingly, many self-centered motivation comments revolved around the participants' beliefs about who they were as teachers. These roles and responsibilities revealed individualized ideas: "In the classroom, I see myself as a facilitator. I believe students are scared and often don't want to admit that they just don't know everything," "I see myself as a coach, I am there to give them information and help student practice in a structured setting," and "I am an entertainer in the sense that I can get students to unknowingly learn."
The student-centered motivation was defined as wanting to help students learn, another intrinsic motivator. Participant responses revolved around preparing students for their profession or engaging them in the learning process. They voiced their desire to pass on their knowledge to new practitioners, shape student identify, and engage them in the learning process. Examples of this included: "I think the most important thing I can leave students with is the knowledge of how to find information and answers to questions," "Learning is a lifelong skill that needs to be fostered in students," and "Students are eager to learn, especially if content is conveyed to them as relevant."

Program design is defined as external motivations that encouraged participants to be part of the HELP program. Comments centered on the content and format of HELP with three subcategories emerging: coursework, timeframe, and online format. Coursework was defined as responses from participants which addressed content, assignments, or activities in HELP. Participants modeled new knowledge on discussion boards and peer evaluation of peers' work. Examples included: "The discussion board conversations with colleagues was critical to my learning" and "Allowing us time to explore many different instructional technologies and teaching methods worked the best for me. .." The timeframe category emerged as participants commented on the HELP schedule, when HELP was offered, or their availability. Responses about flexible learning through a self-paced online environment and timing during the slower summer months stood out. Examples of this included: "Offering HELP during the summer really helped me, I had more time to dedicate to my own learning," and "I run a full time pharmacy and hold a full time faculty position, so my time is already precious." Motivation for the online format was expressed as comments about ease and accessibility. Communication and presence of the instructors and peers in discussion board conversations were discussed as well. Examples of this included, "Accessing an online course while working was valuable," "I have never taken a self-paced course before, it was hard to get motivated, but once I got into it - it worked," and "It was great to have access to the instructors and peers throughout the course for support and to bounce ideas off of."

\section{DISCUSSION}

The purpose of this study was to create a motivational theory that described why pharmacy faculty or staff members pursue professional development in pedagogical knowledge. Pharmacy educators in this study that were fueled by a combination of intrinsic and extrinsic motives. Previous literature on content knowledge professional development programs point to intrinsic and extrinsic 


\section{American Journal of Pharmaceutical Education 2016; 80 (8) Article 132.}

motivates as well; however, our study exposed specific details and concerns unique to this cohort. ${ }^{1,3,20-25}$

Intrinsic factors of motivation centered on a passion for learning, both the faculty member's learning (selfcentered motivation) and students' learning (studentcentered motivation). These internal motivations suggest that success of faculty development programs in pedagogy is closely related to the views and beliefs of individual faculty members. This has implications for the development of future programs designed to teach pharmacy educators about pedagogy. First, it suggests that to promote the importance of faculty development in higher education, programs need to appeal to faculty members' value of learning, to their desire to improve student learning, and to their beliefs about their roles and responsibilities. Second, these internal motives suggest that health educators must first value pedagogical knowledge as necessary and important for their continued growth and development as teachers. Motives of HELP participants recognized teaching development as important, and they demonstrated their commitment toward the professorate. This connection between ideas reveals the link between content knowledge and pedagogy knowledge (PCK) in the TPACK framework. ${ }^{4-8,30,33,34}$ By understanding the motives of faculty members who are naturally drawn to pedagogy knowledge and its intersection with content knowledge, programs can be designed to appeal to these specific motivations. To improve teaching behavior among all faculty members, different targeting or marketing techniques may need to be used.

Revisiting professional development design is important to engage faculty participation. Faculty members must perceive the content as interesting, useful, or important, and they must see value in the learning environment. Participants specifically expressed value in content and format within HELP. In addition, professional development timeframe emerged as an important external motive, as most identified release time was not available when considering to attend HELP. The online self-paced nature of HELP and it being offered during less hectic summer months, may have effected decisions to participate. Balancing time to participate in professional development programs is a barrier. ${ }^{1-3,9-11,20-25}$ Narrowing in on time constraints, needs, and concerns for pharmacy faculty and staff members would be an interesting future study.

Administrator involvement or encouragement of life-long learning in pedagogy might be necessary (as an external motivator) and the key for faculty members to understand and recognize their needs. Having funds available for faculty members to pursue pedagogically focused professional development might be an excellent practice for administrators and could promote attendance.
In addition, the cost of HELP was reasonably priced, suggesting designers should not set professional development program costs too high, as this could reduce appeal and funding availability.

Results from this study can be encapsulated into a motivational model for pharmacy educators (Figure 2). This model, which the authors have coined Pedagogical Knowledge Acquisition Theory (PKAT), is a blended intrinsic and extrinsic motivational model which may predict pharmacy educator's pursuit of pedagogical knowledge. The model is an interesting fit between unique qualities for the cohort of pharmacy educators working in higher education and 2) human behavior elements connected with adult learning successes and barriers. Additional research is needed to confirm this motivational model in a larger, more heterogeneous group of faculty members. Further, a more diverse group beyond pharmacy could shed light on whether PKAT is similar across health educators and other higher education faculty members when considering whether to attend pedagogically focused professional development programs. ${ }^{27-29}$

One potential limitation of the study was that it was conducted with a group of faculty members who were all students in HELP. That they were all in the same program and had similar experiences may have influenced how they responded in the postmodule quizzes and survey. Second, recall bias may have impacted survey results as participants had already completed the program. Finally, the survey had a low response rate of $44 \%$. One contributing factor may have been the contact information used for the 2010 and 2011 cohorts. Work e-mail addresses were used, and it is possible that some participants had changed jobs since completion of HELP. However, the group that responded was representative of the total cohort. Participants were similar in that they were faculty members at pharmacy schools and expressed similar goals and teaching roles in their introductory statements when commencing HELP.

\section{SUMMARY}

Faculty development in pedagogy is not mandatory but is becoming increasingly important in pharmacy education. Understanding what motivates faculty members

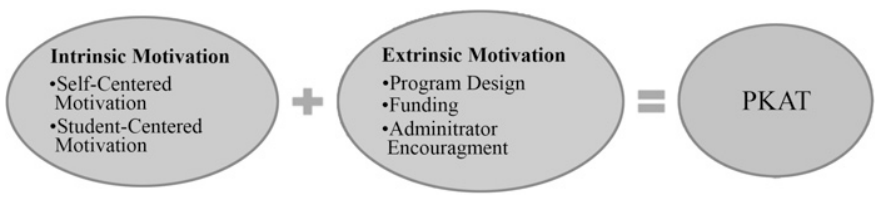

Figure 2. A New Model of Motivation: Pedagogy Knowledge Acquisition Theory (PKAT). 


\section{American Journal of Pharmaceutical Education 2016; 80 (8) Article 132.}

to pursue additional training can be useful when developing these programs. Our study of HELP participants revealed pharmacy educators are highly driven by internal motivations, as well as by content of the program and time needed for learning. The PKAT emerged as a blended intrinsic and extrinsic model of motivation. This model may have value in developing future professional development programs in pedagogy.

\section{REFERENCES}

1. Bower EA, Choi D, Becker TM, Girard DE. Awareness of and participation in maintenance of professional certification: a prospective study. J Contin Educ Health Prof. 2007;27(3):164-172. 2. Guglielmo BJ, Edwards DJ, Franks AS, et al. A critical appraisal of and recommendation for faculty development. Am J Pharm Educ. 2011;75(6):Article 122.

3. Hanson AL, Bruskiewitz RH, Demuth JE. Pharmacists' perceptions of facilitators and barriers to lifelong learning. Am J Pharm Educ. 2007;71(4):Article 67.

4. Koehler MJ, TPACK. Technological pedagogical content knowledge. [Internet] 2012 [cited 2015 June 1]2012. http://www.tpack.org.

5. Shulman L. Those who understand: knowledge growth in teaching. Educ Res. 1986;15(2):4-14.

6. Shulman L. Knowledge and teaching: foundations of the new reform. Harvard Educ Rev. 1987;57(1):1-23.

7. Camblin LD, Steger JA. Rethinking faculty development. High Educ. 2000;39(1):1-18.

8. Strang AF, Baia P. An investigation of teaching and learning programs in pharmacy education. Am J Pharm Educ. 2016;80(4): Article 59.

9. Romanelli F, Smith KM, Brandt BF. Certificate program in teaching for pharmacy residents. Am J Health Syst Pharm.

2001;58:896-898.

10. Romanelli F, Smith KM, Brandt BF. Teaching residents how to teach: a scholarship of teaching and learning certificate program (STLC) for pharmacy residents. Am J Pharm Educ. 2005;69(2): Article 20.

11. Selander LK, Bjornson DC. Description of an elective PharmD teaching clerkship. Am J Pharm Educ. 1995;59(3):273-278.

12. Hammer DP, Paulsen SM. An innovative clerkship in pharmacy education. Am J Pharm Educ. 2001;65(3):284-293.

13. Sylvia LM. An advanced pharmacy practice experience in academia. Am J Pharm Educ. 2006;70(5):Article 97.

14. Garrison GD, Baia P, Canning JE, Strang AF. An asynchronous learning approach for the instructional component of a dual-campus pharmacy resident teaching program. Am J Pharm Educ. 2015;79(2): Article 29.

15. Accreditation Council for Pharmacy Education. About ACPE. Accessed July 21, 2015. https://www.acpe-accredit.org/standards/.

16. American Association of Colleges of Pharmacy. Special Interest Groups. Accessed July 21, 2015. http://www.aacp.org/governance/ SIGS.
17. American Colleges of Clinical Pharmacy. Practice and Research Networks. Accessed July 21, 2015. https://www.accp.com/about/ prns.aspx.

18. Miller J, Bligh J, Stanley I, al Shehri A. Motivation and continuation of professional development. Brit J Gen Prac. 1998;48 (432):1429-1432.

19. Stafford RE, Dreesen EB, Charles A, Marshall H, Rudisill M, Estes E. Free and local continuing medical education does not guarantee surgeon participation in maintenance of certification learning activities. Am Surg. 2010;76(7):692-696.

20. Allaire AS, Labrecque M, Giguere A, Gagnon MP, Legare F. What motivates family physicians to participate in training programs in shared decision making? J Contin Educ Health Prof. 2012;32 (2):98-107.

21. Rosenbaum ME, Ferguson K, Lenoch S. A teaching scholars program to improve faculty development. Acad Med. 2001;76 (5):572-573.

22. Dolcourt JL, Zuckerman G, Warner K. Learners' decisions for attending pediatric grand rounds: a qualitative and quantitative study. BMC Med Educ. 2006; 6:26.

23. Segovis CM, Mueller PS, Rethlefsen ML, et al. If you feed them, they will come: a prospective study of the effects of complimentary food on attendance and physician attitudes at medical grand rounds at an academic medical center. BMC Med Educ. 2007;7:22.

24. Power A, Grammatiki A, Bates I, et al. Factors affecting the views and attitudes of Scottish pharmacists to continuing professional development. Int J Pharm Prac. 2011;19(6):424-430.

25. Driesen A, Leemans L, Baert H, Laekeman G. Flemish community pharmacists' motivation and views related to continuing education. Pharm World Sci. 2005; 27(6):447-52.

26. Creswell JW. Qualitative Inquiry and Research Design: Choosing Among Five Approaches. Thousand Oaks, CA: Sage Publications, Inc.; 2006.

27. Hanson JL, Balmer DF, Giardino AP. Qualitative research methods for medical educators. Acad Ped. 2011;11(5):375-386. 28. Sullivan GM, Sargeant J. Qualities of qualitative research: part 1. $J$ Grad Med Educ. 2011;3(4):449-452.

29. Sargeant J. Qualitative research part II: participants, analysis, and quality assurance. J Grad Med Educ. 2012;4(1):1-3.

30. Baia P. The trend of commitment: pedagogical quality and adoption. In: D’Agustino S. Adaption, Resistance and Access to Instructional Technologies. Fordham University, USA: IGI Global; 2011:273-315.

31. McNaught C, Lam P. Using Wordle as a supplementary research tool. The Qualitative Report. 2010;15(3);630-643.

32. Miley F, Read A. Using word clouds to develop proactive learners. J Scholar Teach Learn. 2011;11(2):91-110.

33. Harris J, Mishra P, Koehler MJ. Teachers' technological pedagogical content knowledge and learning activity types:

curriculum-based technology integration reframed. J Res Tech Educ. 2009;41(4):393-416.

34. Laurillard D. Rethinking university teaching: a conversational framework for the effective use of learning technologies. 2nd ed. London: Routledge Falmer; 2002. 